\title{
ELECCIÓN DE LEY APLICABLE Y JURISDICCIÓN PARA EL RÉGIMEN ECONÓMICO MATRIMONIAL Y LOS EFECTOS PATRIMONIALES DE LAS UNIONES REGISTRADAS: RIESGOS ASOCIADOS ${ }^{1 *}$
}

\author{
Francesco Giacomo Viterbo ${ }^{2 *}$ \\ Profesor titular de Derecho privado (Salento) \\ E-mail: francesco.viterbo@unisalento.it \\ ROBERTO GARETTO \\ Profesor adjunto de Derecho civil (Camerino) \\ E-mail: roberto.garetto@unicam.it
}

\begin{abstract}
RESUMEN: El objetivo de este trabajo es analizar los principales riesgos asociados tanto al momento como al contexto específico en el que se celebra el acuerdo sobre la electio fori y/o la elección de la ley aplicable al régimen económico matrimonial o a los efectos patrimoniales de las uniones registradas.

Palabras clave: acuerdo, ley aplicable, régimen económico matrimonial, efectos patrimoniales de las uniones registradas.
\end{abstract}

\begin{abstract}
The purpose of this chapter is to analyse the main risks associated with both the timing and the specific context in which the agreement on electio fori and/or the choice of law applicable to the matrimonial property regime or the property consequences of registered partnerships is concluded.
\end{abstract}

Keywords: agreement, applicable law, matrimonial property regime, property consequences of registered partnerships.

\footnotetext{
SUMARIO: I. INTRODUCCIÓN II. RIESGOS RELACIONADOS CON EL MOMENTO Y EL “CONTEXTO” GENERAL DE LA ELECCIÓN DE LA LEY Y LA JURISDICCIÓN: OBSERVACIONES PRELIMINARES. III. RIESGOS ASOCIADOS A UNA ELECCIÓN HECHA ANTES O EN EL MOMENTO DE LA CELEBRACIÓN DEL MATRIMONIO O DE LA UNIÓN REGISTRADA. IV. RIESGOS DE UNA ELECCIÓN TARDÍA, REALIZADA DURANTE EL MATRIMONIO O LA UNIÓN REGISTRADA. V. LA CUESTIÓN DE SI SE ADMITE UNA ELECCIÓN IMPLÍ́CITA O TÁCITA DE LA LEY APLICABLE. VI. EL “CONTEXTO” QUE RODEA LA ELECCIÓN DE LA LEy. El ENFOQue pSicológico de las CUESTIONES JURídicas. 6.1. Profesionales del derecho. 6.2. ¿Hay una parte débil que deba ser protegida? ¿quién es? VII. RIESGOS asociados a UN ASESORAMIENTo JURÍDICo INADECUADo aNTES DEL ACUERDo Y SALVAGUARDIAS PARA PROTEGER A LA PARTE MÁS DÉbIL. VIII. OBSERVACIONES FINALES.

1 * Traducido por Ana María Pérez Vallejo, Profesora Titular de Derecho civil y Nuria Martínez Sánchez, Doctora en el departamento de Derecho civil de la Universidad de Almería.

2 * Autores: Francesco Giacomo Viterbo es el autor de las secciones I., II., III., IV., V., VII. y VIII.; y Roberto Garetto es el autor de las secciones VI., 6.1. y 6.2. Traducido por Ana María Pérez Vallejo y Nuria Martínez Sánchez (UAL).
} 


\section{INTRODUCCIÓN}

El Reglamento sobre el régimen económico matrimonial ${ }^{3}$ y el Reglamento sobre los efectos patrimoniales de las uniones registradas ${ }^{4}$ (en adelante, los Reglamentos gemelos) se inscriben en la creciente tendencia a valorar la autonomía privada y la libertad de contratación como factor de conexión para la determinación de la ley aplicable en el seno de las familias transfronterizas de la UE. ${ }^{5}$ Con la adopción de estos reglamentos, la Unión Europea ha reforzado las opciones de elección de ley para los cónyuges y parejas de hecho con respecto a las consecuencias patrimoniales de los matrimonios y las uniones registradas. Esta posibilidad puede combinarse con la previsión de mecanismos de elección de foro para lograr la concentración de la jurisdicción y la ley, y simplificar así el marco jurídico de referencia. ${ }^{6}$ En efecto, las partes pueden no sólo elegir la ley aplicable a su régimen patrimonial (professio iuris), sino también atribuir la competencia a la autoridad del mismo Estado cuya ley es aplicable.

La autonomía de la voluntad de las partes es un importante instrumento del Derecho internacional privado de familia de la UE. Las partes están en condiciones de hacer la elección óptima que mejor se adapte a su situación concreta; de ajustar su conducta y de prever las consecuencias jurídicas asociadas. Esto también conduce a una mayor seguridad jurídica, estabilidad y previsibilidad de las soluciones, ya que se pueden evitar

3 Reglamento (UE) 2016/1103 del Consejo, de 24 de junio de 2016, por el que se establece una cooperación reforzada en el ámbito de la competencia, la ley aplicable, el reconocimiento y la ejecución de resoluciones en materia de regímenes económicos matrimoniales. OJ L 183/1 [2016].

4 Reglamento (UE) 2016/1104 del Consejo, de 24 de junio de 2016, por el que se establece una cooperación reforzada en el ámbito de la competencia, la ley aplicable, el reconocimiento y la ejecución de resoluciones en materia de efectos patrimoniales de las uniones registradas. DO L 183/30 [2016].

5 Sobre el papel de la autonomía privada en las legislaciones familiares nacionales, véanse los informes nacionales en J.M. Scherpe (coord), Marital Agreements and Private Autonomy in Comparative Perspective, Hart, Oxford 2012. Sobre la evolución del papel de la autonomía privada en el Derecho internacional privado de la familia en la Unión, véase J. Gray, Party Autonomy in EU Private International Law. Choice of Court and Choice of Law in Family Matters and Succession, Intersentia, Cambridge 2021, pp. 15-33; P. Kinsch, 'Les fondements de l'autonomie de la volonté en droit national et en droit européen' in en A. Panet, H. Fulchiron y P. Wautelet (eds) (coords), L'autonomie de la volonté dans les relations familiales internationales, Bruylant, Bruxelles 2017, pp. 17-22; D. Henrich, 'Zur Parteiautonomie im europäisierten internationalen Familienrecht' in en A. Verbeke, J.M. Scherpe, C. Declerck, T. Helms y P. Senaeve (eds) (coords), Confronting the frontiers of family and succession law: liber amicorum Walter Pintens, vol. 1, Intersentia, Antwerp 2012, pp. 701-14; P. Gannagé, 'La Pénétration de l'autonomie de la volonté dans le droit international privé de la famille' [1992] Revue critique de droit international privé $425,425-39$.

6 La autonomía de las partes es más limitada en lo que respecta a la jurisdicción. El mecanismo de elección del tribunal no es el principal factor de conexión, ya que la concentración de la jurisdicción se considera prioritaria. De acuerdo con los artículos 4 y 5 de los Reglamentos gemelos, cuando un tribunal de un Estado miembro sea competente en materia de sucesión de un cónyuge en virtud del Reglamento de sucesiones, o para resolver una demanda de divorcio, separación judicial o nulidad matrimonial en virtud del Reglamento de Bruselas II a, los tribunales de dicho Estado serán competentes para resolver las cuestiones de régimen económico matrimonial que se planteen en relación con dichas demandas, siempre que, en determinados casos, exista un consentimiento específico de las partes a la concentración. Sólo en el caso de que ningún tribunal de un Estado miembro sea competente en virtud de los artículos 4 o 5 , o en casos distintos de los previstos en dichos artículos, se aplica el mecanismo de elección de foro con preferencia al paralelismo de forum y ius en virtud del artículo 7. Sobre el principio de concentración, que es el principal criterio para determinar la competencia, lo que hace que la aplicación del mecanismo de elección de foro sea residual, véase L. Ruggeri, en M.J. Cazorla González, M. Giobbi, J. Kramberger Škerl y L. Ruggeri (coords), Property Relations of Cross-Border Couples in the European Union, Edizioni Scientifiche Italiane, Napoli 2020, p. 60; P. Bruno, I regolamenti europei sui regimi patrimoniali dei coniugi e delle unioni registrate. Commento ai Regolamenti (UE) 24 giugno 2016, nn. 1103 e 1104 applicabili dal 29 gennaio 2019, Giuffrè, Milano 2019, p. 102. Véase también el capítulo 4 de este volumen. 
fácilmente los costes y retrasos derivados de la necesidad de identificar la ley aplicable sobre la base de factores de conexión objetivos.

Sin embargo, el ejercicio de la autonomía por parte de las parejas en un contexto transfronterizo no está exento de riesgos e incertidumbre en cuanto a cómo y hasta qué punto puede llevarse a cabo en la práctica, lo que puede limitar o poner en peligro los beneficios mencionados.

El objetivo de este capítulo es analizar los principales riesgos asociados tanto al momento como al contexto específico en el que se celebra el acuerdo sobre la electio fori y/o la elección de la ley aplicable al régimen económico matrimonial o a los efectos patrimoniales de las uniones registradas.

\section{RIESGOS RELACIONADOS CON EL MOMENTO Y EL "CONTEXTO" GENERAL DE LA ELECCIÓN DE LA LEY Y LA JURISDICCIÓN: OBSERVACIONES PRELIMINARES}

Deberíamos empezar analizando el momento en el que se celebran los acuerdos de elección de ley y de elección de foro. De hecho, el momento es muy importante, ya que el momento de la elección puede tener otras implicaciones en más de un aspecto.

En primer lugar, el considerando 45 del Reglamento sobre el régimen económico matrimonial y el considerando 44 del Reglamento sobre las consecuencias patrimoniales de las uniones registradas especifican que los cónyuges y las parejas registradas, respectivamente, están autorizados a elegir la ley aplicable a las consecuencias patrimoniales de su relación "en cualquier momento": los cónyuges, "antes del matrimonio, en el momento de la celebración del matrimonio o durante el matrimonio"; las parejas, "antes del registro, en el momento del registro o durante la vigencia de la unión registrada". En consonancia con estas disposiciones, la redacción del apartado 1 del artículo 22 habla de "cónyuges o futuros cónyuges" y de "miembros o futuros miembros de una unión registrada". 7

La técnica utilizada por el legislador europeo en los Reglamentos gemelos es muy similar a la de los anteriores Reglamentos en materia de familia. Los cónyuges pueden acordar la designación de la ley aplicable a la separación judicial y al divorcio "en cualquier momento, pero no posteriormente a la fecha en la que se interponga la demanda ante un órgano jurisdiccional”, según los apartados 1 y 2 del artículo 5 del Reglamento Roma III. ${ }^{8}$ El artículo 8 del Protocolo de La Haya de 23 de noviembre de 2007 sobre la Ley Aplicable a las Obligaciones Alimenticias establece que el acreedor y el deudor de alimentos pueden "en cualquier momento" elegir la ley aplicable a su relación. ${ }^{9}$

Al redactar los Reglamentos gemelos, el legislador europeo pensó principalmente en las parejas que, en algún momento de su matrimonio o de su relación de pareja, modifi-

7 C. Kohler, Choice of the Applicable Law, en P. Franzina and y I. Viarengo (coords), The EU Regulations on the Property Regimes of International Couples. A Commentary, Edward Elgar Publishing, Cheltenham 2020, p. 201.

8 A. Zanobetti, 'Divorzio all'europea. Il regolamento UE Rome III sulla legge applicabile allo scioglimento del matrimonio e alla separazione personale' [2012] La nuova giurisprudenza civile commentata 250, 255-57.

9 Cursiva añadida. Esta disposición permite a las partes elegir la ley aplicable a la obligación de mantenimiento en cualquier momento e incluso antes de que surja un litigio: A. Bonomi, Explanatory Report on the Hague Protocol of 23 November 2007 on the law applicable to maintenance obligations, HCCH Publications, The Hague 2013, p. 53. 
caban sus circunstancias personales en un aspecto relevante para el Reglamento, es decir, cambiando de nacionalidad o, más comúnmente, trasladando su residencia habitual a otro Estado. Desde esta perspectiva, la única forma de dar seguridad a la regulación de estas relaciones es tomar una instantánea de la situación de la pareja en el momento en que se celebra el acuerdo de professio iuris y electio fori. ${ }^{10}$

Del apartado 1 del artículo 7 y del apartado 1 del artículo 22 de los Reglamentos gemelos se desprende que el momento en el que se celebra el acuerdo determina el objeto de la elección disponible para la pareja, es decir, el abanico de leyes (y de tribunales) elegibles. ${ }^{11}$ De los apartados 2, 3 y 4 del artículo 23 de los Reglamentos gemelos se desprende que el momento en que se celebra el acuerdo también determina los requisitos formales adicionales para la validez del acuerdo, en su caso.

Pensemos en una pareja de ciudadanos griegos que se casan en Italia y trasladan allí su residencia habitual. Al cabo de unos años se trasladan a España, donde también adquieren la nacionalidad española, pero unos años después se instalan en Portugal. Si acordaran la ley aplicable en el "período italiano", la elección estaría limitada entre la ley griega y la italiana, y en cada caso habría que comprobar que el acuerdo cumple los requisitos formales de validez establecidos por la ley italiana. Si, por el contrario, celebrasen el acuerdo en el "periodo portugués", el abanico de opciones ya no incluiría la ley italiana (que es la ley aplicable hasta que las partes hagan una elección), sino la griega, la española y la portuguesa, y en cada caso habría que comprobar que el acuerdo cumple los requisitos formales de validez establecidos por la ley portuguesa. ${ }^{12}$

Otro factor relevante que debe tenerse en cuenta es la forma en que la pareja realiza la elección de la ley y la jurisdicción y, en particular, las circunstancias en que se celebra el acuerdo. ${ }^{13}$ En este sentido, los Reglamentos gemelos hacen hincapié en los requisitos formales del acuerdo, con mucho menos énfasis en el "contexto" en el que las partes toman la decisión. ${ }^{14}$

No obstante, algunos riesgos para la pareja o para la parte más débil de la pareja pueden derivarse de su enfoque fáctico de las cuestiones jurídicas, así como de una asistencia jurídica inadecuada por parte del profesional del derecho (por ejemplo, notario, abogado) en el que las partes han confiado. Algunas incertidumbres relativas a la cele-

10 Para simplificar el análisis que sigue, se omitirán los problemas relacionados con el hecho de que el matrimonio o la unión registrada se haya celebrado antes o después de la entrada en vigor de los Reglamentos gemelos.

11 Los Reglamentos gemelos permiten a los cónyuges y a las parejas registradas elegir "entre las leyes con las que tengan una estrecha conexión en razón de su residencia habitual o de su nacionalidad", según el considerando 45 del Reglamento de régimen económico matrimonial y el considerando 44 del Reglamento sobre los efectos patrimoniales de las uniones registradas. Además, los miembros registrados pueden elegir "la ley del Estado conforme a cuya ley se haya creado la unión registrada", de conformidad con el artículo 22, apartado 1, letra c), del Reglamento sobre las consecuencias patrimoniales de las uniones registradas.

12 Además, véase el considerando 47 del Reglamento sobre el régimen económico matrimonial, según el cual Si, en la fecha de celebración del acuerdo, "los cónyuges tienen su residencia habitual en Estados miembros diferentes que establecen requisitos formales distintos, bastará con que se respeten los requisitos formales de uno de esos Estados. Si, en la fecha de celebración del acuerdo, solo uno de los cónyuges tiene su residencia habitual en un Estado miembro que establece requisitos formales adicionales, estos deben respetarse".

13 Sobre esta cuestión, véanse los apartados 5 y 7.

14 Sobre esta cuestión, véanse los apartados $6,6.1$ y 6.2 . 
bración del acuerdo pueden surgir de la cuestión de si la designación de la ley aplicable tiene que ser explícita o también puede ser implícita. Esto podría ocurrir cuando las partes estipulan un acuerdo por el que organizan su régimen patrimonial tras el matrimonio o la unión registrada sin una elección expresa de la ley.

Otros riesgos también pueden estar relacionados con las interacciones entre los actuales instrumentos de la UE sobre los bienes matrimoniales, las uniones registradas, el divorcio, la separación legal y las obligaciones de alimentos, todos los cuales exigen un mayor margen de autonomía dentro del derecho de familia. ${ }^{15}$

\section{RIESGOS ASOCIADOS A UNA ELECCIÓN HECHA ANTES O EN EL MOMENTO DE LA CELEBRACIÓN DEL MATRIMONIO O DE LA UNIÓN REGISTRADA}

La principal ventaja de la elección de la ley aplicable prevista en el artículo 22 es garantizar la estabilidad y la previsibilidad de la ley aplicable. Si las partes han llegado a un acuerdo de este tipo, la ley elegida sigue siendo aplicable a pesar de cualquier cambio en sus situaciones personales, e independientemente de la autoridad a la que se recurra en caso de litigio. En particular, el cambio de la residencia habitual de la pareja no provoca un cambio de la ley aplicable, a diferencia de lo que ocurre en caso de ausencia de elección en virtud del artículo 26 de los Reglamentos gemelos.

La posibilidad ofrecida a los Estados miembros vinculados por los Reglamentos gemelos de imponer requisitos formales adicionales para que el acuerdo sea válido introduce, sin embargo, un elemento de incertidumbre en el mecanismo de elección de la ley. La validez del acuerdo podría ser impugnada mucho tiempo después de su celebración por iniciativa de uno de los cónyuges o socios que tenga interés en la aplicación de una ley diferente.

La identificación de la residencia habitual de la pareja en el momento de la elección es una operación que, en el caso de las parejas transfronterizas, puede ser objeto de valoraciones contradictorias. La noción de "residencia habitual" debe interpretarse de forma autónoma. Se trata de una situación de hecho basada en un "vínculo genuino" entre el individuo y el Estado y, en las relaciones familiares, adopta la forma del lugar en el que "existen indicadores sintomáticos vinculados a la continuidad de la vida de la pareja o a la intención de las partes de organizar la vida en común". ${ }^{16}$ Sin embargo, su valoración debe hacerse teniendo en cuenta todos los aspectos del caso concreto, a la luz del contexto particular en el que debe operar el criterio. ${ }^{17}$ Este criterio está vinculado a un lugar

15 Para más detalles, véase el apartado 7.

16 Asunto C-279/93, Finanzamt Köln-Altstadt v. Schumacker, ECLI:EU:C:1995:31; Asunto C-391/97, Gschwind v. Finanzamt Aachen-Außenstadt, ECLI:EU:C:1999:409; Asunto C-87/99, Patrik Zurstrassen v. Administration des contributions directes, ECLI:EU:C:2000:251. Para más detalles sobre el concepto de "residencia habitual" en las relaciones familiares, véase M. Giobbi, in en M.J. Cazorla González, M. Giobbi, J. Kramberger Škerl y L. Ruggeri (coords), arriba n. 4, pp. 75-81.

17 Asunto C-497/10 PPU, B. Mercredi v. R. Chaffe, ECLI:EU:C:2010:829, point 47. Para un análisis más amplio de la jurisprudencia, véase A. Limante, 'Establishing Habitual Residence of Adults under the Brussels IIa Regulation: Best Practices from National Case-Law' [2018] Journal of Private International Law 160-81. El adjetivo "habitual" indica el requisito de una cierta permanencia y estabilidad y, por tanto, podría implicar la condición de un cierto paso del tiempo para calificar una resi-dencia. Sin embargo, el TJUE sostuvo que once 
que puede cambiar fácil y rápidamente con el tiempo, dando lugar a incertidumbres en su aplicación. En este caso, para la validez del acuerdo, bastaría con el cumplimiento de las normas formales de uno de los estados vinculados a la vida de la pareja. Esta solución parece ser coherente con el principio de preservación del acto de autonomía privada, que es una constante en la legislación europea. ${ }^{18}$

Además, la elección de la ley y del forum antes o en el momento del matrimonio o de la unión registrada puede tener otros inconvenientes. Si pasa mucho tiempo después de la celebración del acuerdo y hay que iniciar un procedimiento judicial, la ley aplicable y el tribunal competente siempre se identifican mirando al pasado con el riesgo de que en el momento de presentar la solicitud, ningún cónyuge o pareja tenga ya una conexión concreta con ese estado concreto. Si consideramos el ejemplo anterior, la pareja griega podría perder la conexión con Italia durante el periodo portugués. Sin embargo, una posible solución a este problema la ofrece el propio Reglamento, al especificar que la pareja puede cambiar en cualquier momento la ley aplicable, aunque dicho cambio por parte de los cónyuges o miembros de la unión registrada "no debe surtir efectos retroactivos, salvo disposición contraria expresa por su parte". ${ }^{19}$ De este modo, las parejas dinámicas tienen la oportunidad de adaptar la ley aplicable a las consecuencias patrimoniales de su matrimonio o pareja a su cambio de vida y a sus circunstancias personales actuales. ${ }^{20}$

Dado que las partes están expresamente autorizadas a elegir la ley aplicable antes de la celebración del matrimonio o de la unión registrada, la autonomía de las partes podría verse obstaculizada si la ley designada es la de un Estado que limita los acuerdos prenupciales que prevén la división de los bienes en caso de divorcio. Por otra parte, si las partes designan la ley aplicable con el único propósito de vincularse a un acuerdo prenupcial permitido por esa ley, el acuerdo completo puede no ser válido en virtud de la lex fori debido a su incompatibilidad con el orden público (ordre public).

Sin embargo, estos riesgos parecen haberse mitigado en gran medida en la UE.

En algunos Estados miembros, las dificultades que surgieron durante el siglo $\mathrm{XX}$, en relación con la idea de que los acuerdos que preveían consecuencias en caso de separación o divorcio eran contrarios al orden público y nulos, parecen haberse

años de residencia de un ciudadano irlandés en Alemania, causados por una necesidad médica, no eran suficientes para considerar modificada la residencia habitual anterior (Asunto C 255/13, I c. Health Service Executive, ECLI:EU:C:2014:1291). Según otra perspectiva, el adjetivo serviría principalmente para evitar que una mera estancia ocasional, aunque sea prolongada en el tiempo, se considere "residencia". Esto puede no ser cierto. Una persona que se traslada de una residencia anterior, que es abandonada, a una nueva puede adquirir inmediatamente la residencia habitual en el nuevo lugar de habitación sin necesidad de que transcurra ningún lapso de tiempo. Lo que importa son las características del caso concreto, que deben evaluarse caso por caso, aunque es innegable que la duración de la estancia puede ser un elemento útil para evaluar la residencia habitual: A. Zanobetti, 'La residenza abituale nel diritto internazionale privato: spunti di riflessione' [2019] 2, Liber Amicorum Angelo Davì. La vita giuridica internazionale nell'età della globalizzazione 1361, pp. 1399-402.

18 See L. Ruggeri, vid. supra n. 4, p. 67. De acuerdo con otra opinión, sería aconsejable, en el momento del acuerdo, cumplir con los requisitos formales más estrictos que puedan establecer los ordenamientos jurídicos con los que los cónyuges tienen puntos de contacto importantes en sus vidas, para evitar que el acuerdo corra entonces el riesgo de ser considerado inválido: A. Zanobetti, vid. supra n. 6, p. 256.

19 Véase el considerando 46 del Reglamento sobre el régimen económico matrimonial y el considerando 45 del Reglamento sobre las consecuencias patrimoniales de las uniones registradas.

20 L. Rademacher, 'Changing the past: retroactive choice of law and the protection of third parties in the european regulations on patrimonial consequences of marriages and registered partnerships' [2018] vol. $10 \mathrm{n}^{\circ} 1$ Cuadernos de Derecho Transnacional 7, 15. 
superado definitivamente. Un buen ejemplo es el caso del Reino Unido, ${ }^{21}$ donde "los tribunales siempre han adoptado un enfoque más matizado respecto a los acuerdos prenupciales y postnupciales", "otorgando cierto peso, y en algunas circunstancias, decisivo, a los acuerdos prenupciales". ${ }^{22}$ Por otra parte, cabe señalar que incluso en aquellos Estados miembros en los que el Derecho de familia interno sigue siendo un obstáculo para la admisibilidad de los acuerdos prenupciales, los tribunales han considerado que tales restricciones legales no se aplican a los acuerdos celebrados por parejas internacionales. Es emblemático el caso de Italia, donde el Tribunal de Casación afirmó la compatibilidad con el orden público internacional de un acuerdo celebrado entre dos cónyuges estadounidenses residentes en Italia que pretendían regular sus relaciones patrimoniales mutuas en caso de divorcio. ${ }^{23}$

Desde una perspectiva más general, ciertos riesgos pueden estar asociados a una optio legis que permite a las partes celebrar acuerdos que no están permitidos por la lex fori ${ }^{24}$ Esta cuestión puede resolverse teniendo en cuenta la reciente decisión del TJUE en el caso $J E$ contra $K F .{ }^{25}$ En aplicación del principio enunciado en dicha sentencia, cabe considerar que, si el tribunal competente considera que la ley extranjera aplicable en virtud de las disposiciones de los Reglamentos gemelos permite la celebración de acuerdos prenupciales, mientras que la lex fori no prevé tal opción, dicho tribunal debe, no obstante, determinar si se cumplen los requisitos de fondo previstos en la ley extranjera aplicable y hacer esta constatación en el marco del procedimiento del que conoce.

21 Para más información, consulte N. Lowe, 'Prenuptial agreements. The Developing English Position' in en A. Verbeke, J.M. Scherpe, C. Declerck, T. Helms y P. Senaeve (coords), arriba n. 3, pp. 867-85.

22 See Radmacher (Formerly Granatino) v Granatino [2010] UKSC 42, [2010] 2 FLR 1900, point 62. En el concurso de jurisdicciones de derecho común para las que la institución del régimen económico matrimonial es desconocida como tal, el juez puede tener en cuenta las disposiciones de un contrato matrimonial celebrado con arreglo al derecho extranjero, que, sin embargo, no es vinculante para el derecho inglés.

23 Cass. civ., 3 Mayo 1984, n. 2682, en Giurisprudenza italiana, 1984, p. 370. Para un análisis reciente de esta cuestión, véase G. Perlingieri and y G. Zarra, Ordine pubblico interno e internazionale tra caso concreto e sistema ordinamentale, Edizioni Scientifiche Italiane, Napoli 2019. En Italia, la tesis de que los acuerdos prenupciales en previsión de separación y divorcio son nulos se ha basado en la interpretación del artículo 160 del Código Civil. Sin embargo, la opinión contraria se impone en la doctrina: véase G. Chiappetta, 'La «semplificazione» della crisi familiare: dall'autorità all'autonomia' en P. Perlingieri y S. Giova (coords), Comunioni di vita e familiari tra libertà, sussidiarietà e inderogabilità, Edizioni Scientifiche Italiane, Napoli 2019, pp. 435 ss.; T.V. Russo, 'I contratti prematrimoniali' in en F.G. Viterbo and y F. Dell'Anna Misurale (coords), 'Nuove sfide del diritto di famiglia. Il ruolo dell'interprete' [2018] Quaderni di «Diritto delle successioni e della famiglia» 193, pp. 193-222; G. Oberto, 'Contratti prematrimoniali e accordi preventivi sulla crisi familiare' [2012] Famiglia e diritto 69, 69-103.

24 Consideremos como ejemplo el artículo 42 de la Ley de Familia croata, según el cual no se puede elegir la ley extranjera como aplicable a las relaciones patrimoniales mediante contrato matrimonial. Sobre esta restricción de la autonomía de la voluntad, véase D. Vrbljanac, 'The Matrimonial Property Regime Regulation: selected issues concerning applicable law. Working paper' en J. Kramberger Škerl, L. Ruggeri y F.G. Viterbo (coords), 'Case studies and best practices analysis to enhance EU Family and Succession Law. Working Paper' [2019] 3 Quaderni degli Annali della Facoltà Giuridica dell'Università di Camerino 185, pp. 192-96.

25 Asunto C-249/19, $J E$ contra $K F$, ECLI:EU:C:2020:570, punto 43, donde se afirma el siguiente principio: "en una situación como la que es objeto del litigio principal, en la que el tribunal competente considera que la ley extranjera aplicable en virtud de las disposiciones del Reglamento Roma III únicamente permite solicitar el divorcio si este ha ido precedido de una separación judicial de una duración de tres años, mientras que la ley del foro no contempla normas de procedimiento en materia de separación judicial, dicho tribunal debe, no obstante, ya que no puede declarar él mismo tal separación, comprobar que se cumplen las condiciones de fondo previstas en la ley extranjera aplicable y hacerlo constar en el marco del procedimiento de divorcio del que conoce". 


\section{RIESGOS DE UNA ELECCIÓN TARDÍA, REALIZADA DURANTE EL MATRIMONIO O LA UNIÓN REGISTRADA}

Una elección de ley realizada antes o en el momento de la celebración del matrimonio o de la unión registrada tiene intrínsecamente un efecto sólo prospectivo. El régimen económico matrimonial (tanto si se establece por ley como si se basa en un acuerdo particular de las partes) comienza con el matrimonio (registro de la pareja).

Si la ley aplicable al régimen económico matrimonial o a los efectos patrimoniales de una unión registrada es designada por la pareja durante el transcurso de la relación, por ejemplo, algunos años después de la celebración del matrimonio o de la unión registrada, la elección de la ley acordada por las partes tiene por objeto cambiar la ley aplicable a sus relaciones patrimoniales. En efecto, hasta la conclusión del acuerdo, las relaciones patrimoniales se rigen por la ley designada en virtud del artículo 26 de los Reglamentos gemelos. La cuestión es si, en el período anterior al acuerdo de elección de ley, el derecho a, por ejemplo, las compras realizadas por uno de los cónyuges o miembros de la unión registrada debe depender de la ley aplicada en el momento de la compra, o si la ley designada ex post por las partes de conformidad con el artículo 22 de los Reglamentos gemelos tiene prioridad y se aplica retrospectivamente. A este respecto, ambos Reglamentos establecen que un cambio de la ley aplicable "solo surtirá efectos en el futuro" salvo acuerdo en contrario de las partes, de conformidad con el apartado 2 del artículo 22. Esto significa que la 'nueva' ley también puede tener efecto retroactivo siempre que las partes así lo estipulen expresamente. ${ }^{26}$ Además, este cambio retroactivo de la ley aplicable no puede "perjudicar los derechos de terceros" derivados de la ley (y del régimen de propiedad) anterior, según el apartado 3 del artículo 22 de los Reglamentos gemelos. ${ }^{27}$

Es necesario centrarse en los dos posibles escenarios mencionados anteriormente. El primer escenario se plantea cuando las partes acuerdan expresamente un cambio retroactivo de la ley aplicable. Naturalmente, esta solución no afectará a los derechos de propiedad a los que se puso fin antes de la celebración del acuerdo. Por ejemplo, todos y cada uno de los bienes vendidos por la pareja antes de la celebración del acuerdo de elección de ley siguen estando sujetos a la ley vigente en el momento de la enajenación, en virtud del principio tempus regit actum..$^{28}$ Por otra parte, los derechos patrimoniales adquiridos por cada cónyuge o pareja durante la vigencia del régimen económico matrimonial anterior (por ejemplo, los bienes comprados después del matrimonio pero antes del cambio de ley aplicable) estarán sujetos a la aplicación de la "nueva" ley elegida por las partes.

El segundo escenario se plantea cuando las partes acuerdan cambiar la ley aplicable sin estipular el efecto retroactivo de la ley elegida. En otras palabras, se establece que la ley aplicable se aplicará sólo en el futuro.

Uno de los problemas que surgen en esta situación es la fragmentación de las leyes que rigen las relaciones patrimoniales de las partes. La ley designada en virtud del artículo 26 de los Reglamentos gemelos - es decir, en la mayoría de los casos la ley del

26 Véase el considerando 46 del Reglamento N. 1103 y el considerando 45 del Reglamento N. 1104.

27 El cambio del pasado también puede producirse a expensas de terceros. Sobre este tema, véase D. Martiny, 'The Effects of Marital Property Agreements in Respect of Third Parties' en A. Verbeke, J.M. Scherpe, C. Declerck, T. Helms y P. Senaeve (coords), arriba y n. 3, pp. 903-27; L. Rademacher, arriba n. 18, 7-11.

28 N. Cipriani, 'Rapporti patrimoniali tra coniugi, norme di conflitto e variabilità della legge applicabile' [2009] 1 Rassegna di diritto civile 19, 54. 
Estado de la "primera residencia habitual común" después del matrimonio o "la ley del Estado conforme a cuya ley se haya creado la unión registrada" - se aplicará hasta la celebración del acuerdo de elección de ley. A partir de entonces, se aplicará a sus relaciones patrimoniales la ley designada por las partes. Sin embargo, la mayoría de las legislaciones familiares nacionales prevén normas que hacen necesaria la disolución y liquidación de un régimen patrimonial que deja de regir un matrimonio o una pareja de hecho. Dicha liquidación no suele redundar en beneficio de los cónyuges o parejas y se considera una complicación indeseable. ${ }^{29}$

Otro problema puede surgir si las partes han celebrado previamente un acuerdo matrimonial o un acuerdo de propiedad de la pareja con arreglo a la ley de un Estado en el que no tienen su "primera residencia habitual común".

Consideremos el caso de dos ciudadanos italianos que viven en Alemania y conciertan su matrimonio en Italia, donde firman un acuerdo por el que optan por el régimen de "separación de bienes" de conformidad con los artículos 215 y siguientes del Código Civil italiano. Continúan viviendo en Alemania durante varios años y finalmente deciden establecerse en Italia, donde celebran un acuerdo por el que optan por la ley italiana sin especificar su efecto retroactivo. La pareja podría pensar que, de conformidad con sus acuerdos, la ley italiana se aplica en general a sus relaciones matrimoniales. Sin embargo, esto no es necesariamente así. La voluntad de las partes es un elemento importante para estabilizar la regulación adecuada de sus relaciones patrimoniales. No obstante, se plantea la cuestión de si el anterior acuerdo matrimonial celebrado por las partes en Italia en el momento de su matrimonio puede interpretarse como un acuerdo implícito de elección de ley, con el resultado de que la ley italiana se aplica también a sus relaciones patrimoniales antes de su traslado a Italia. En caso contrario, se aplicaría a esas relaciones la ley de la primera residencia habitual común, es decir, la ley alemana.

Esta cuestión se analizará en la siguiente sección. Sin embargo, una solución hermenéutica destinada a reforzar la autonomía de las partes podría motivar una interpretación diferente del artículo 22 de los Reglamentos gemelos. Cuando esta disposición se refiere a la libertad de las partes para "cambiar la ley aplicable", podría interpretarse que sólo abarca el cambio de la ley elegida por las partes sobre la base de un acuerdo anterior, pero no de la ley aplicable en virtud del artículo 26 de los Reglamentos gemelos. La noción de "cambio de la ley aplicable" excluiría así el caso de una designación de la ley aplicable realizada con posterioridad al momento en que se celebra el matrimonio o la unión registrada. En tal caso, la elección de la ley aplicable también tendría un efecto retroactivo, a menos que las partes acuerden lo contrario.

El TJUE, interpretando el apartado 3 del artículo 4 del Protocolo de La Haya de 2007 sobre la Ley Aplicable a las Obligaciones Alimenticias, ${ }^{30}$ declaró recientemente que "el inconveniente que supone la aplicación de leyes distintas en sucesivos procedimientos seguidos entre las mismas partes parece ínsito al sistema de normas de conflicto". ${ }^{31}$ Lo

29 L. Rademacher, vid supra n. 18, 15.

30 Protocolo de La Haya de 23 de noviembre de 2007 sobre la ley aplicable a las obligaciones alimentarias.

31 Asunto C-214/17, Alexander Mölk v. Valentina Mölk, ECLI:EU:C:2018:744. El Tribunal de Justicia declaró que “el artículo 4, apartado 3, del Protocolo de La Haya contempla únicamente la situación en la que el acreedor elige indirectamente la ley del foro en el ámbito de un procedimiento entablado por él mismo ante la autoridad competente del Estado de residencia habitual del deudor, y no se extiende a un procedimiento posterior, incoado 
mismo podría decirse del riesgo de aplicar leyes diferentes en un mismo procedimiento entre las mismas partes en el sistema de normas de conflicto de leyes establecido en los Reglamentos gemelos. No obstante, estos riesgos deben limitarse siempre que sea posible una interpretación diferente de las normas pertinentes en función de los derechos que deben protegerse. No se trata sólo de evitar una fragmentación del régimen patrimonial de la pareja, sino de prevenir el riesgo de que se plantee la elección de la ley aplicable a las relaciones patrimoniales en su conjunto y en el momento en que surja la necesidad de una liquidación de intereses.

\section{LA CUESTIÓN DE SI SE ADMITE UNA ELECCIÓN IMPLÍCITA O TÁCITA DE LA LEY APLICABLE}

Las partes pueden acordar la designación o el cambio de la ley aplicable mientras dure el matrimonio o la unión registrada, en última instancia en los procedimientos de divorcio o disolución de la unión. ${ }^{32}$ Tampoco puede descartarse que el acuerdo sobre la ley aplicable al régimen económico matrimonial o las consecuencias patrimoniales de la unión registrada formen parte de la negociación de las condiciones generales de la separación o el divorcio. En efecto, por una parte, las partes podrían no ser conscientes de esta oportunidad hasta la ruptura de su relación; por otra parte, el acuerdo previo podría no reflejar las necesidades y circunstancias de las partes en el momento del divorcio (o la separación). En ambos casos, las partes discutirán las posibles soluciones para estas situaciones.

En primer lugar, la concentración de la competencia tiene prioridad. De conformidad con el artículo 4, se prevé la concentración de la competencia en caso de fallecimiento de uno de los cónyuges. El artículo 5 de los Reglamentos gemelos establece que cuando se acuda a un tribunal de un Estado miembro para resolver una demanda de divorcio, separación judicial o nulidad matrimonial en virtud del Reglamento Bruselas II a, los tribunales de dicho Estado serán competentes para resolver las cuestiones de régimen económico matrimonial o los efectos patrimoniales de la unión registrada que se planteen en relación con dichas demandas. Además, en determinados casos, será necesario un acuerdo específico entre las partes sobre la concentración. ${ }^{33}$

Un punto que requiere claridad se refiere a la situación en la que la pareja ha concluido previamente un acuerdo sobre la ley aplicable a la separación y el divorcio de

una vez que la resolución adoptada en el procedimiento inicial haya pasado en autoridad de cosa juzgada". Esta interpretación es criticable, ya que, como sostiene el Gobierno portugués, conduce a la paradoja de que las solicitudes concurrentes relativas a un breve período durante el cual no se ha producido ningún cambio en la residencia habitual de las partes deban examinarse con arreglo a distintos ordenamientos jurídicos. Cabe destacar que, en un procedimiento posterior iniciado por el deudor, la determinación de la ley aplicable debería depender de la elección inicial de la ley y el foro realizada por el acreedor en virtud del apartado 3 del artículo 4 del Protocolo de La Haya, de conformidad con su objetivo de proteger al acreedor, considerado la parte más débil en sus relaciones con el deudor.

32 C. Kohler, vid supra n. 5, p. 201 s.

33 Los casos mencionados son los previstos en el apartado 2 del artículo 5 del Reglamento sobre el régimen económico matrimonial. Por otra parte, el artículo 5, apartado 1, del Reglamento sobre las consecuencias patrimoniales de las uniones registradas establece que "Cuando se someta a un órgano jurisdiccional de un Estado miembro la disolución o anulación de una unión registrada, los órganos jurisdiccionales de dicho Estado miembro serán competentes para resolver sobre los efectos patrimoniales de la unión registrada que tengan conexión con la disolución o anulación de esta última", cuando sus miembros así lo acuerden. 
conformidad con las disposiciones del Reglamento Roma III, pero después de la entrada en vigor de los Reglamentos gemelos no ha concluido ningún otro acuerdo. Se plantea la cuestión de si, en tal caso, la ley designada por la pareja en previsión de la separación y el divorcio puede considerarse aplicable también a las consecuencias patrimoniales del matrimonio o de la unión registrada. Esto significa aclarar si se puede suponer que las partes han hecho una elección implícita y, sin embargo, aceptable en este sentido, incluso en ausencia de su solicitud expresa.

Se ha señalado que la cuestión de si la designación de la ley aplicable ha de ser explícita o puede ser también implícita ha de recibir una respuesta uniforme, sobre la base de una "interpretación autónoma" del concepto de "acuerdo" con arreglo al apartado 1 del artículo 22 de los Reglamentos gemelos. ${ }^{34}$ Así, la elección de la ley aplicable debe ser "expresa o claramente demostrada por los términos del contrato o las circunstancias del caso". ${ }^{35}$ Sin embargo, este punto de vista conlleva algunos riesgos.

Volvamos al caso de la pareja italiana que organiza su matrimonio en Italia pero tiene su residencia habitual en Alemania. Consideremos las dos situaciones siguientes:

\section{$\underline{\text { Supuesto A }}$}

En el momento de contraer matrimonio, celebraron un acuerdo matrimonial ante un notario italiano en el que se designaba como régimen económico matrimonial la "separación de bienes" según el artículo 215 y siguientes del Código Civil italiano. Se puede argumentar que la elección de la ley italiana como ley aplicable en virtud del artículo 22, apartado 1, del Reglamento de régimen económico matrimonial debe quedar claramente demostrada por los términos de dicho acuerdo. ${ }^{36}$

\section{$\underline{\text { Supuesto B }}$}

Después del matrimonio, celebraron un acuerdo de elección de ley ante un notario alemán designando la ley alemana como la ley aplicable al divorcio y a la separación judicial de conformidad con el artículo 5, apartado 1, del Reglamento Roma III. ¿Podrían estas circunstancias demostrar que la ley alemana es la ley que las partes han elegido aplicar a sus relaciones, incluyendo implícitamente el régimen económico matrimonial?

En ambos ejemplos, cabe señalar que los "términos del acuerdo" y las "circunstancias" indicadas en cada supuesto no parecen suficientes para responder a la cuestión de si equivalen a un acuerdo implícito sobre la elección de la ley aplicable al régimen económico matrimonial de conformidad con el artículo 22, apartado 1, del Reglamento sobre el régimen económico matrimonial. La definición de lo que es un acuerdo de elección de ley de conformidad con el apartado 1 del artículo 22 es un punto que debe evaluarse sobre la base de los criterios y requisitos establecidos en los artículos 22 a 24 y los considerandos

34 C. Kohler, vid. supra n. 5, p. 201 s.

35 Ibídem, p. 202. El autor justifica esta solución interpretativa con una referencia al apartado 1 del artículo 3 del Reglamento Roma I, donde se plantea la misma cuestión. En su opinión, "no hay ninguna razón plausible para no admitir, en virtud del apartado 1 del artículo 22, una elección claramente demostrada por los términos de un acuerdo entre las partes o por las circunstancias que lo rodean". 
pertinentes de los Reglamentos gemelos, así como los que se dejan al derecho nacional. A la luz de este enfoque, el considerando 47 del Reglamento sobre el régimen económico matrimonial y el considerando 46 del Reglamento sobre las consecuencias patrimoniales de la unión registrada merecen una atención especial. Estos considerandos señalan que las normas sobre la validez material y formal de un acuerdo de elección de ley establecidas en los Reglamentos gemelos tienen por objeto facilitar la "elección informada" 37 de los cónyuges o parejas y garantizar que "son conscientes de las consecuencias de su elección". ${ }^{38}$

Una vez señalado esto, ¿se puede estar seguro de que en los dos ejemplos citados los cónyuges hicieron una elección realmente informada de la ley aplicable al régimen económico matrimonial? No, pero es muy improbable que este requisito se cumpla en el supuesto B, mientras que sólo es posible en el supuesto A. En ambos supuestos, la información que las partes recibieron del notario antes o en el momento en que celebraron el acuerdo debe determinarse a la luz del contexto concreto que rodea su elección. Los cónyuges deben ser debidamente informados por el notario no sólo de la posibilidad de elegir entre la ley alemana y la italiana, sino también de las implicaciones de esta elección a la vista de los regímenes matrimoniales de dichas leyes. Esta información o actividad de asesoramiento debe quedar clara en el contenido del acuerdo.

Así, un acuerdo implícito de la pareja sobre la ley aplicable al régimen económico matrimonial o las consecuencias patrimoniales de la unión registrada sólo puede admitirse si se demuestra que las partes tuvieron la oportunidad de elegir con verdadera información sobre la gama de opciones y sus implicaciones, sobre la base de un asesoramiento jurídico adecuado. Por lo tanto, en el supuesto A, si no se facilitó esta información a las partes, su acuerdo de patrimonio matrimonial no puede interpretarse como un acuerdo de elección de la ley aplicable. De ello se desprende que si unos años más tarde las partes optan por aplicar la ley italiana a su régimen económico matrimonial sin un acuerdo expreso sobre su efecto retroactivo, la ley alemana se aplicará a sus relaciones matrimoniales antes del cambio de ley aplicable.

Teniendo en cuenta estos argumentos y el hecho de que el artículo 23 de los Reglamentos gemelos establece normas específicas sobre la validez formal del acuerdo, por regla general la elección o el cambio de la ley aplicable no pueden ser tácitos. ${ }^{39}$

Nada impide que el cónyuge o los miembros de la pareja celebren un acuerdo de elección de la ley que regule sus relaciones patrimoniales en el momento en que se recurra al tribunal o ante el tribunal durante el curso del procedimiento. ${ }^{40} \mathrm{Sin}$ embargo, este acuerdo procesal sobre la elección de la ley aplicable podría no concluirse tácitamente mediante la demanda presentada por uno de los cónyuges o miembros de la pareja ante

37 Esta redacción se utiliza en ambos considerandos. Se ha añadido la cursiva.

38 Esta redacción se utiliza en ambos considerandos. Cursiva añadida. Cabe destacar que estos requisitos no se establecen para el acuerdo de elección de foro.

39 Sobre este punto, véase P. Bruno, vid. supra n. 4, p. 183; K. Zabrodina, 'The law applicable to property regimes and agreements on the choice of court according to Regulations (EU) 1103 and 1104 of 2016' in en J. Kramberger Škerl, L. Ruggeri y F.G. Viterbo (eds) (coords), arriba n. 22, pp. 199 s.

40 De conformidad con el apartado 3 del artículo 5 del Reglamento Roma III, los cónyuges también pueden designar la ley aplicable ante el tribunal en el curso del procedimiento, "si la ley del foro así lo establece". Hay que señalar que esta disposición no está presente en los Reglamentos gemelos, pero no hay ninguna razón para impedir que los cónyuges designen la ley ante el tribunal en el curso del procedimiento, independientemente de lo que disponga la ley del forum. 
el tribunal para invocar la aplicación del régimen patrimonial previsto por dicha ley y la falta de oposición del otro cónyuge o miembro de la pareja en la primera defensa. En tal caso, corresponde al tribunal llamar la atención de las partes sobre la ley aplicable y examinar si han sido informadas de las implicaciones de su elección, tal y como exige los Reglamentos gemelos.

El importante papel otorgado a la autonomía privada obliga a verificar rigurosamente la presencia de un acuerdo claro y expreso alcanzado por las partes sobre la ley aplicable. ${ }^{41}$

\section{EL "CONTEXTO" QUE RODEA LA ELECCIÓN DE LA LEY. EL ENFOQUE PSICOLÓGICO DE LAS CUESTIONES JURÍDICAS}

Mientras que en otros sectores, como el comercio, el planteamiento de las cuestiones jurídicas suele tener un nivel de conciencia más profundo, en lo que respecta a la familia, esto no siempre es así.

A este nivel se puede identificar un punto crítico. En efecto, el derecho de familia combina cada vez más los aspectos emocionales con el enfoque patrimonial que caracteriza a otros ámbitos del derecho. Al celebrar un matrimonio o establecer una pareja registrada, los aspectos jurídicos relacionados con las relaciones patrimoniales son a menudo descuidados por la pareja que tiende a centrarse más en la dimensión afectiva y relacional. ${ }^{42}$ Sólo en una fase posterior de disolución del matrimonio (o de la unión registrada) se tiene en cuenta de forma significativa la esfera jurídica. ${ }^{43}$

Por supuesto, el régimen económico matrimonial también es relevante cuando el matrimonio va bien (así como las consecuencias patrimoniales, en el caso de las uniones registradas). El régimen patrimonial, en efecto, puede afectar negativamente a los derechos de terceros (por ejemplo, los acreedores de uno de los cónyuges o de las parejas registradas). ${ }^{44}$

Hay que tener en cuenta que la mayoría de las veces, los miembros de la pareja tienden a no estar especialmente atentos, incluso en los casos en que se negocian los aspectos patrimoniales de su relación. Psicológicamente, se supone que los cónyuges o miembros de la unión registrada no contemplan de forma realista los riesgos de ruptura, ni consideran las adversidades que pueden ocurrir en el futuro de la pareja. ${ }^{45}$ Únicamente

41 L. Ruggeri en M.J. Cazorla González, M. Giobbi, J. Kramberger Škerl y L. Ruggeri (coords), vid. supra n. 4, p. 66. Así lo confirma la jurisprudencia del TJUE: véase el Asunto C-387/98, Coreck Maritime GmbH c. Handelsveem $B V$ and others, ECLI:EU:C:2000:606, punto 13; Asunto C-543/10, Refcomp Refcomp SpA c. Axa Corporate Solutions Assurance SA, ECLI:EU:C:2013:62, puntos 27-28.

42 J. Wightman, 'Intimate relationships, relational contract theory, and the reach of contract' [2000] 8 Feminist Legal Studies, 93, 112.

43 K. Baker, 'Property Rules Meet Feminist Needs: Respecting Autonomy by Valuing Connection' [1998] 59 Ohio State Law Journal, 1523, 1578.

44 La protección particular de los acreedores que ofrece el régimen comunitario es a menudo controvertida, principalmente entre los estudiosos del derecho común. Véase A.B. Carroll, 'The Superior Position of the Creditor in the Community Property Regime: Has the Community Become a Mere Creditor Collection Device' [2007] 47 Santa Clara Law Review, 1, 2: 'Creditor protection may be a worthy societal goal, at least generally speaking. But the community regime has gone so far to provide such protection that it has significantly departed from its teleology'.

45 G. Levinger, 'A Social Psychological Perspective on Marital Dissolution' [1976] 32 Journal of Social Issues, 21, 37: 'A firmly committed spouse does not yearn for separation and may never even think of divorce.' 
en caso de fallecimiento o divorcio, la elección realizada respecto a la ley aplicable y la jurisdicción parece ser esencial.

Independientemente del estado de ánimo, cuando la pareja opta por la elección de la ley y/o la jurisdicción, está implícito que la elección realizada es en interés de ambas partes. Hay que tener en cuenta la posibilidad de que el acuerdo persiga la conveniencia personal de una sola de las partes. En ocasiones, la conveniencia puede consistir en fines particulares referidos a un sistema jurídico específico. ${ }^{46}$ Otras veces, el objetivo puede ser simplemente reducir los costes relacionados con posibles juicios futuros.

Sin embargo, existe un riesgo real de que una de las partes obtenga más ventajas de la elección de la ley (y de la jurisdicción) en detrimento de la otra parte, y que ésta no sea consciente de ello. ${ }^{47} \mathrm{El}$ recurso a profesionales como los consultores reduce este riesgo.

\subsection{Profesionales del derecho}

Dado que la elección de la ley aplicable, que requiere el apoyo de profesionales del derecho, implica costes, las partes suelen evaluar si los beneficios que se pueden obtener mediante el ejercicio de la autonomía - en el caso concreto - justifican el gasto. ${ }^{48}$ Por lo tanto, las partes difícilmente se verán inducidas a la elección de la ley aplicable si pueden obtener efectos ventajosos para ellas incluso en ausencia de su elección. La estructura de los Reglamentos gemelos antepone la posibilidad de elegir la ley (artículo 22) a la disposición relativa a la ley aplicable a falta de elección de las partes (artículo 26). Sin embargo, esta sucesión lógica no corresponde a la situación más recurrente. En la mayoría de los casos, la ley aplicable será la derivada de la conexión objetiva, y sólo si los efectos previsibles de la conexión objetiva no se corresponden con las expectativas de las partes, éstas optarán por la elección de la ley aplicable. ${ }^{49}$

La elección de la ley también depende de la calidad de la información de que dispone la pareja. En condiciones ideales, la pareja debería disponer de información precisa y clara sobre los aspectos jurídicos relacionados con el régimen patrimonial, pero generalmente no es así. La elección de la jurisdicción y de la ley aplicable puede ser potencialmente arriesgada, sin una información adecuada derivada de un examen minucioso de todas las cuestiones jurídicas relacionadas. Este riesgo puede limitarse -como se ha dicho- mediante una asistencia profesional altamente cualificada, que por supuesto puede tener un coste elevado. Sin embargo, el papel de los profesionales que prestan esta asistencia es crucial. ${ }^{50}$

En el momento de la elección de la jurisdicción y/o la ley, no se sabe qué puntos pueden surgir que puedan dar lugar a un litigio en el curso del matrimonio o de la unión registrada, y qué cuestiones se plantearían en caso de divorcio o disolución de la unión. Tam-

46 Vea el estudio de caso en M.J. Cazorla González, 'Ley aplicable al régimen económico matrimonial después de la disolución del matrimonio tras la entrada en vigor del Reglamento UE 2016/1104' [2019] 21 Doctrina y Jurisprudencia, 87, 97-98.

47 R. Montinaro, 'Marital contracts and private ordering of marriage from the Italian family law perspective' [2017] 3 The Italian Law Journal, 75, 86.

48 L. Walker, 'New (and old) Problems for Maintenance Creditors under the Maintenance Regulation' en P. Beaumont, M. Danov, K. Trimmings y B. Yüksel (coords), Cross-Border Litigation in Europe, Hart, London 2017, p. 771.

49 C. Gonzalez Beilfuss, 'Reflexiones en torno a la función de la autonomía de la voluntad conflictual en el derecho internacional privado de familia' [2020] 72 Revista Española de Derecho Internacional, 101, 104.

50 R.A. Brand, Transaction Planning Using Rules on Jurisdiction and the Recognition and Enforcement of Judgments, Brill Nijhoff, Leiden 2014, p. 23. 
poco está siempre claro qué ley se aplicará a la pareja transfronteriza en caso de separación o si una de las partes fallece. La función específica de los profesionales del derecho es crear seguridad a partir de la incertidumbre, previendo los posibles litigios que puedan surgir. Tienen que prever el foro en el que se resolverán los litigios y la ley aplicable a los mismos, en el mejor interés de las partes. Está claro que las competencias que se exigen a estos profesionales son enormes. Además, a menudo no es fácil encontrar profesionales adecuadamente formados. De hecho, los profesionales que trabajan en derecho de familia no suelen tener conocimientos específicos y avanzados en el ámbito del derecho internacional privado y el derecho comparado. ${ }^{51}$ En ciertos contextos, los abogados con competencias adecuadas en estos sectores todavía necesitan una formación adecuada. En ausencia de dicha formación, un profesional puede verse tentado a sugerir la elección de una ley que no es ventajosa para la propia pareja, pero que es preferida por el abogado debido a la familiaridad ${ }^{52}$ que las partes y el profesional tienen hacia un determinado marco normativo. En este sentido, podría inducir a los clientes a optar por la aplicación de la lex fori aunque sea menos ventajosa por sí misma, sólo porque el enfoque profesional es menos complejo.

La autonomía en la elección de la ley aplicable y la jurisdicción es una herramienta que deben utilizar los profesionales para reducir (y a veces eliminar) los riesgos en la eventual ruptura de una relación que implique a una pareja transfronteriza, tanto en caso de matrimonio como de unión registrada. Básicamente, el proceso de toma de decisiones ${ }^{53}$ para los profesionales que consideran las cuestiones de la ley aplicable y la jurisdicción relacionadas con las parejas transfronterizas implica un conjunto de tres preguntas:

- ¿Cuál es la norma por defecto de la ley y la jurisdicción aplicables?

- ¿Podría interesar a las partes cambiar la norma por defecto?

- ¿Qué ley y jurisdicción aplicables servirían mejor a los intereses de las partes?

Plantear y responder a estas preguntas permitirá al profesional determinar cómo reducir o eliminar los riesgos que la ley y la jurisdicción por defecto imponen a las partes.

El proceso de toma de decisiones requeriría que el marco jurídico fuera formal y estable. Esto debería permitir a los profesionales del derecho hacer un diagnóstico preciso y tomar las precauciones necesarias. Sin estos requisitos, es de hecho difícil prever cualquier medida anticipatoria o reducir los riesgos potenciales. El derecho de familia, de todos modos, se acerca y se aleja simultáneamente de tal connotación. ${ }^{54}$

En este contexto de potencial inestabilidad en la relación de las partes (y consiguiente imprevisibilidad), el mayor riesgo que los profesionales deben considerar se refiere a la posibilidad de una escalada del conflicto entre las partes. Esta escalada es especialmente negativa si tenemos en cuenta que las partes -aún estando en posiciones antagónicas- han estado unidas por relaciones familiares (por ejemplo, el vínculo paren-

51 C. Gonzalez Beilfuss, vid. supra n. 47, 105.

52 S. Vogenajer, 'Regulatory Competition Through Choice of Contract Law and Choice of Forum in Europe: Theory and Evidence' [2013] 21 European Review of Private Law, 13, 53: 'choices of law and forum are primarily driven by factors other than the substantive merits of the respective regimes' legal rules. By far the most important factor is the parties' familiarity with the chosen regime'.

53 Véase en general, para el derecho internacional privado: R.A. Brand, arriba n. 48, p. 24.

54 R. Aviel, 'A New Formalism for Family Law' [2014] 55 William \& Mary Law Review, 2003, 2006: 'Family law is simultaneously moving toward and away from formalist decision making'. 
tal), que a menudo persisten. Una cierta previsibilidad jurídica de las consecuencias de una ruptura facilita la reducción del riesgo de conflicto.

\section{2. ¿Hay una parte débil que deba ser protegida? ¿quién es?}

En el sector del derecho privado, las relaciones son tradicionalmente ciegas al género. Esto es el resultado de la construcción de un concepto general de capacidad jurídica y de la creación de un sujeto de derecho único y universal. ${ }^{55}$ Sin embargo, en el contexto de la familia, la relevancia del género todavía se puede notar. ${ }^{56}$ Hay que tener en cuenta, de hecho, que hasta hace unos años, el matrimonio se caracterizaba de forma estructural con respecto al género. ${ }^{57}$

El principio de autonomía de las partes en el Derecho de familia internacional privado presupone que ambas partes tienen el mismo poder de negociación y están igualmente informadas. En este enfoque, dicho principio refleja la idea de igualdad de género.

La sentencia del Tribunal Supremo español de 24 de junio de 2015 es de gran importancia. ${ }^{58} \mathrm{El}$ caso se refería a un acuerdo matrimonial que establecía la separación de bienes. En caso de divorcio, debía pagarse mensualmente a la esposa una cantidad garantizada en forma de renta vitalicia. El Tribunal Supremo no vio ninguna renuncia de derechos (ni una renuncia a la ley aplicable), ya que el acuerdo no se basaba en la necesidad de ninguno de los cónyuges ni en el desequilibrio tras la crisis del matrimonio, ya que ambas partes gozaban de una condición económica saludable. No se había impuesto la sujeción de una de las partes y no había pruebas de que el acuerdo hubiera sido gravemente perjudicial para el marido. El Tribunal Supremo alude al profundo cambio de modelo social y matrimonial actual que exige un mayor margen de autonomía dentro del derecho de familia y considera que el acuerdo no es contrario a la ley, la moral o el orden público, ya que no afecta a la igualdad de los cónyuges.

Esto plantea, sin embargo, la cuestión de la protección efectiva de la parte más débil. La cuestión es muy amplia en sí misma, ya que el desequilibrio es una característica común de muchas relaciones entre particulares, en particular debido a la desigualdad de poder y al diferente grado de conocimiento de que disponen las partes. ${ }^{59}$ En consecuencia,

55 A. Grear, "Sexing the Matrix": Embodiment, Disembodiment and the Law: Towards the Re-Gendering of Legal Personality' en J. Jones, A. Grear, R.A, Fenton y K. Stevenson (coords), Gender, Sexualities and Law, Routledge, London 2011, p. 49.

56 M.R. Marella, 'Gli accordi fra coniugi fra suggestioni comparatistiche e diritto interno', en G. Ferrando (coord), Separazione e divorzio. Giurisprudenza sistematica civile e commerciale fondata da Bigiavi, Utet, Torino 2003, p. 157.

57 S.A. Hill, Families: A Social Class Perspective, SAGE, Los Angeles 2012, p. 9: 'Although defining marriage and enforcing marriage rules were often difficult, there was substantial agreement across cultures on one point: Men were to be the dominant partner in the marriage or the heads of their families, and wives were to be subservient and obedient to their husbands'. De la misma manera, K. Baker, vid. supra n. 41, p. 1525.

58 Tribunal Supremo, 24 Junio 2015, Roj: STS 2828/2015 - ECLI: ES:TS:2015:2828. See A.M. Pérez Vallejo, 'Waiver of economic benefits on premarital agreement with cross-border dimension' in en J. Kramberger Škerl, L. Ruggeri y F.G. Viterbo (coords), arriba n. 22, pp. 154 s. More widely on the decision: Id. 'Notas sobre la aplicación del Reglamento (UE) 2016/1103 a los pactos prematrimoniales en previsión de la ruptura matrimonial' [2019] 21 Revista Internacional de Doctrina y Jurisprudencia, 105, $115 \mathrm{~s}$.

59 O.O. Cherednychenko, Fundamental Rights, Contract Law and the Protection of the Weaker Party: A Comparative Analysis of the Constitutionalisation of Contract Law, With Emphasis on Risky Financial Transactions, Sellier European Law Pub, München 2007, p. 14. 
una amplia lista de sujetos pueden ser considerados como la parte más débil. También hay que señalar que -en una perspectiva comparada- se suele prestar poca atención a la necesidad de considerar el desequilibrio de poder entre las partes como una cuestión relacionada con los derechos fundamentales de la persona. ${ }^{60}$

Ya no se puede decir a priori que la mujer tiene menos poder de negociación en la pareja, ni que el hombre tiene más poder sólo por ser hombre. Sin duda, la mujer puede ser la parte más fuerte de la relación. Esta es, por ejemplo, la situación que dio lugar a un caso "emblemático": Radmacher (Formerly Granatino) contra Granatino. ${ }^{61}$ Una mujer alemana muy rica, la Sra. Radmacher, y un hombre francés, el Sr. Granatino, celebraron un acuerdo prenupcial que establecía que ninguna de las partes podía reclamar los bienes separados de la otra. Nueve años después de la boda, el marido, que entretanto había dejado un trabajo bien remunerado para iniciar una carrera académica menos lucrativa, reclamó una compensación accesoria contra los bienes de la esposa. Sin embargo, el Tribunal rechazó la demanda y dictaminó que el acuerdo prenupcial era válido. Además, hay que tener en cuenta que la variedad taxonómica ${ }^{62}$ de las parejas casadas o registradas también puede afectar potencialmente a las cuestiones relacionadas con los roles de género: una pareja puede estar compuesta por dos mujeres o dos hombres. Todas estas consideraciones llevan a reconocer que, en el contexto familiar, la situación de la parte más débil debe identificarse caso por caso, sin estereotipos a priori: tanto la esposa como el esposo pueden ser potencialmente la parte más débil.

La relación entre un comerciante y un consumidor o entre un empleador y un empleado es mucho más clara en términos de equilibrio de poder: un consumidor y un empleado, por lo general, tienen menos poder contractual que sus contrapartes. Este desequilibrio conlleva el riesgo de que la elección de la ley aplicable sea impuesta por la parte más fuerte, en detrimento de la parte más débil. Lo mismo no puede decirse con una certeza similar en el ámbito familiar, especialmente a la luz de la reciente evolución de la taxonomía en el derecho de familia. En efecto, las relaciones familiares no son tan sencillas como las comerciales. A menudo se caracterizan por la desigualdad de poder de negociación, pero las desigualdades pueden ser diferentes en relación con diferentes cuestiones. Uno puede estar en una posición más fuerte desde el punto de vista económico, pero el otro puede estar en una posición más fuerte en relación con los hijos y con el hogar en el que viven. Uno puede preocuparse más por conseguir o conservar la mayor cantidad de dinero posible, mientras que el otro puede preocuparse más por las condiciones de vida de los hijos. Uno puede querer salir de la relación lo antes posible, mientras que el otro puede no tener prisa por separarse o divorciarse.

Esto requiere una cuidadosa reflexión sobre la propia noción de debilidad, que está estructuralmente relacionada con la condición de vulnerabilidad. ${ }^{63}$ Una definición de vulnerabilidad que combina elementos internos y externos puede ser la siguiente "estar expuesto a la posibilidad de sufrir un daño siendo sustancialmente incapaz de proteger-

60 Ibid.

61 Radmacher (Formerly Granatino) v Granatino [2010] UKSC 42, [2010] 2 FLR 1900. Sobre la cuestión del cónyuge más débil en el caso Granatino, véase J.M. Scherpe, 'Fairness, Freedom and Foreign Elements - Marital Agreements in England and Wales after Radmacher v Granatino' [2011] 23 Child and Family Law Quarterly, 513, 521 s.

62 R. Garetto en M.J. Cazorla González, M. Giobbi, J. Kramberger Škerl y L. Ruggeri (coords), vid. supra n. 4, p. 87.

63 E. Gilson, The Ethics of Vulnerability: A Feminist Analysis of Social Life and Practice, Routledge, NewYorkLondon 2014, pp. 8-9. 
se". ${ }^{64}$ La vulnerabilidad no constituye un estado intrínseco de una parte y no de la otra, sino que concierne a cada miembro de la pareja de manera diferente. ${ }^{65}$ En ciertos casos, ambos miembros de la pareja pueden ser partes débiles y/o vulnerables incluso simultáneamente, dependiendo de las circunstancias del caso concreto.

Paralelamente a la vulnerabilidad, parece oportuno considerar también la situación de dependencia. Toda persona, desde su nacimiento, está destinada a estar en estado de dependencia en diferentes fases de su existencia. La vulnerabilidad corresponde al estado de dependencia que se constituye concretamente y que a menudo no es previsible de antemano. Estas situaciones de dependencia son relevantes para la pareja y requieren diferentes consideraciones según las circunstancias del caso concreto, ya que la vulnerabilidad tiene múltiples facetas. Puede estar relacionada con aspectos económicos, culturales, sociales y psicológicos. Es cierto que, por ejemplo, la parte de un sexo (en las parejas heterosexuales), la parte cuya nacionalidad está relacionada con determinadas zonas geográficas, o la parte más joven (en el caso de una disparidad de edad considerable en la pareja) pueden encontrarse con frecuencia en una posición económica más débil. Sin embargo, la dinámica de la pareja puede establecer equilibrios compensatorios internos que hacen referencia a la vulnerabilidad de la otra parte. En efecto, hay que tener en cuenta factores vinculados, por ejemplo, a la autonomía individual, a la esfera psicológica y relacional y a la salud. Estos factores pueden ser relevantes para la pareja y crear estados de dependencia recíprocos. Estas situaciones pueden darse en cualquier etapa de la relación y pueden evolucionar constantemente. ${ }^{66}$

Cuando se plantea la cuestión del divorcio, la vulnerabilidad desempeña un papel importante. Las partes pueden tener la tentación de dirigir su conducta en el plano emocional, a veces renunciando a lo que se les debe por un sentimiento de culpa, y otras veces planteando exigencias sobre la base de un sentimiento de venganza. Esto puede determinar el riesgo de que una de las partes intente prevaricar contra la otra, que se encuentra en una situación especialmente vulnerable.

Sin embargo, también es posible que las partes sigan en términos pacíficos aunque la relación se rompa. ${ }^{67}$ De esta manera no se alterará el equilibrio entre las situaciones de mayor y menor vulnerabilidad de las partes.

\section{RIESGOS ASOCIADOS A UN ASESORAMIENTO JURÍDICO INADECUADO ANTES DEL ACUERDO Y SALVAGUARDIAS PARA PROTEGER A LA PARTE MÁS DÉBIL}

Hay que tener en cuenta el "contexto" general que rodea la elección de la ley aplicable. Esto implica la necesidad de evaluar el abanico de opciones disponibles para la pareja a la luz de ciertas tendencias recientes del Derecho de familia europeo.

64 D. Schroeder y E. Gefenas, 'Vulnerability: Too Vague and Too Broad?' [2009] 18 Cambridge Quarterly of Healthcare Ethics, 113, 116.

65 M.A. Fineman, 'Why Marriage?' [2001] 9 Virginia Journal of Social Policy \& the Law, 239, 242-43: 'marriage can also be seen as serving society by taking care of the dependency and vulnerability of some members of the marital family.'

66 M.A. Fineman, 'Beyond Equality and Discrimination' [2020] 73 SMU Law Review Forum, $51,57$.

67 J. Herring, 'Relational Autonomy and Family Law', en J. Wallbank, S. Choudhry y J. Herring (coords), Rights, Gender and Family Law, Routledge, Abingdon 2010, pp. 266-68. 
En primer lugar, a pesar de que las obligaciones alimentarias entre cónyuges o parejas de hecho deben excluirse del ámbito de aplicación de los Reglamentos gemelos, de acuerdo con su considerando 22, en algunos Estados miembros se tiende a reforzar tanto el objetivo de reequilibrio que persiguen las resoluciones de asignación después del divorcio como el vínculo entre el régimen patrimonial adoptado durante el matrimonio o la unión registrada y los criterios para determinar si se debe dicha asignación y su importe.

En España, el legislador ha dotado a la compensación o pensión compensatoria del artículo 97 del Código Civil, que corresponde al cónyuge para el que la separación o el divorcio ha supuesto un desequilibrio económico en relación con la posición del otro cónyuge, una función reequilibradora ${ }^{68}$ Por otra parte, la compensación económica prevista en el artículo 1438 del Código Civil español forma parte del régimen económico matrimonial primario y está estrechamente relacionada con el deber de los cónyuges de contribuir a la satisfacción de las necesidades familiares; se establece exclusivamente para los casos en que el régimen económico matrimonial es el de "separación de bienes". ${ }^{69}$ En Italia, la sentencia del Tribunal de Casación de 11 de julio de 2018 supone un revulsivo en el caso de la ley que hace que la prestación post divorcio tenga un carácter compuesto, es decir, tanto asistencial como compensatorio. ${ }^{70}$ Por lo tanto, la asignación después del divorcio puede ordenarse como una compensación equitativa por los sacrificios realizados durante el matrimonio por uno de los cónyuges para satisfacer las necesidades familiares. Tanto el derecho a la pensión postdivorcio como la evaluación de su cuantía están anclados en todos los elementos que se enumeran en el apartado 6 del artículo 5 de la ley italiana sobre el divorcio, ${ }^{71}$ incluida la contribución personal y financiera de cada cónyuge al bienestar de la familia y la creación de bienes personales y conjuntos, así como los ingresos de ambos cónyuges. Tanto en el sistema italiano como en el español, se puede conceder una indemnización compensatoria al cónyuge cuyos sacrificios durante el matrimonio hayan sido mucho mayores, permitiendo al otro cónyuge avanzar en su carrera y aumentar sus ingresos netos. El objetivo de reequilibrar las diferencias de medios económicos entre las partes se persigue teniendo en cuenta las consecuencias patrimoniales del matrimonio o de la unión registrada. Esto se aplica independientemente del hecho de que cada uno pueda mantenerse plenamente. ${ }^{72}$

68 Sin embargo, se admite que la pensión compensatoria "se incorpora en sentido amplio al concepto de obligación de alimentos": sobre este punto véase A.M. Pérez Vallejo, vid. supra n. 56, p. 151.

69 El artículo 1438 del Código Civil español trata de paliar las consecuencias negativas que el régimen de separación de bienes tiene sobre el cónyuge que ha trabajado en el hogar. Según algunos autores, dicha compensación no puede configurarse como una pensión alimenticia, por lo que entraría en el ámbito de aplicación del Reglamento de Régimen Económico Matrimonial: ibídem, p. 152.

70 Una revisión en el caso italiano de la ley que hace que los alimentos después del divorcio sean compuestos en naturaleza, es decir, tanto orientados a la asistencia como compensatorios, se debe al Tribunal de Casación, Divisiones Conjuntas, 11 de julio de 2018, núm. 18287 en Giuisprudenza italiana, 2018, pp. 1843-52, with note of C. Rimini, Il nuovo assegno di divorzio: la funzione compensativa e perequativa, ibid., pp. 1852-61. Para una breve descripción de la historia de los cambios entre los jueces e intérpretes en relación con la ley italiana de alimentos después del divorcio, véase G. Terlizzi, “Ties that Bind”: Maintenance Order After Divorce in Italy' [2018] 2 The Italian Law Journal 449, 449-476.

71 Nos remitimos a la ley italiana, 1. 1 de diciembre de 1970, n. 898.

72 En Italia, véase Tribunal de Casación, 17 de febrero de 2021, n. 4224, en Pluris online. 
En este contexto, puede faltar la razón de la conexión con el Estado de la residencia habitual del acreedor prevista en el Protocolo de La Haya de 2007.73 Por lo tanto, es probable que se pregunte al TJUE si, en estos casos, la reclamación de una pensión compensatoria después del divorcio debe estar comprendida en el concepto de "obligaciones alimenticias" y, por lo tanto, en el ámbito de aplicación del Reglamento sobre alimentos y del Protocolo de La Haya sobre la Ley Aplicable a las Obligaciones Alimenticias de 2007, o más bien en el concepto de "régimen económico matrimonial" o de "consecuencias patrimoniales de una unión registrada" y, por lo tanto, en el ámbito de aplicación de los Reglamentos gemelos. ${ }^{74} \mathrm{Al}$ margen de esta cuestión interpretativa, el legislador europeo ya ha subrayado la conexión y coordinación entre estas diferentes materias propias de las relaciones entre cónyuges o parejas, permitiendo a las partes hacer una elección de ley "dependiente", es decir, absorber la ley aplicable a los alimentos en la ley aplicable al régimen patrimonial de las partes o a su separación o divorcio, de conformidad con las letras c) y d) del apartado 1 del artículo 8 del Protocolo de La Haya.

De ello se desprende que corresponde al notario o al otro profesional del Derecho que asiste a las partes en la conclusión del acuerdo sobre la ley aplicable a las consecuencias patrimoniales del matrimonio o de la unión registrada señalar la importancia de la coordinación con la elección de la ley aplicable no sólo a la separación y al divorcio, sino también a las obligaciones alimentarias. ${ }^{75}$ De hecho, el riesgo de inseguridad jurídica y de fragmentación puede surgir si las partes no celebran dicho acuerdo global de elección de la ley. ${ }^{76}$ Sería conveniente un tratamiento unitario de estas cuestiones. Por lo tanto, sólo un asesoramiento jurídico adecuado puede garantizar que la misma ley regule todas ellas. Es posible lograr la coincidencia de la ley aplicable mediante un acuerdo sobre la elección de la ley de la residencia habitual común o de la nacionalidad de uno de los cónyuges o socios en el momento de la designación, tal como se prevé en todos los reglamentos pertinentes de la UE. ${ }^{77}$

$\mathrm{Al}$ acordar la elección de la ley aplicable, las partes prevén el tratamiento de sus relaciones patrimoniales bajo una serie de leyes posibles y finalmente optan por la que

73 En estos casos españoles e italianos, la asignación de una pensión compensatoria debe considerarse como parte de la liquidación del régimen económico matrimonial y no como una obligación de alimentos. Además, la institución del régimen económico matrimonial es ajena a las jurisdicciones de derecho común que tienen normas de reparto de los bienes de los cónyuges tras la disolución del matrimonio. A este respecto, véanse los criterios hermenéuticos establecidos por el TJUE en el asunto Van den Boogaard v. Laumen: Case C-220/95, Antonius van den Boogaard v. Paula Laumen, ECLI:EU:C:1997:91.

74 Sobre la cuestión de cómo debe determinarse la ley aplicable en estos casos, véase F.G. Viterbo, 'Claim for maintenance after divorce: Legal uncertainty regarding the determination of the applicable law' en J. Kramberger Škerl, L. Ruggeri y F.G. Viterbo (coords), vid. supra n. 22, pp. 171-83.

75 A este respecto, véase A. Bonomi, 'The Interactions among the Future EU Instruments on Matrimonial Property, Registered Partnerships and Successions' [2011] vol. 13 Yearbook of Private International Law 217, pp. 217-31; B. Campuzano Díaz, 'The Coordination of the EU Regulations on Divorce and Legal Separation with the Proposal on Matrimonial Property Regimes', ibid. 233, pp. 233-53.

76 Los Reglamentos gemelos no contienen una disposición específica para la coordinación de las leyes aplicables, ya que prevén expresamente la determinación de la jurisdicción: D. Damascelli, 'Applicable law, jurisdiction, and recognition of decisions in matters relating to property regimes of spouses and partners in European and Italian private international law' [2019] Trusts \& Trustees 6, pp. 6-16. Además, no hay coincidencia entre los criterios de identificación de la ley aplicable en ausencia de elección por las partes: véase I. Viarengo, 'Effetti patrimoniali delle unioni civili transfrontaliere' [2018] 54 Rivista di diritto internazionale privato e processuale 33, pp. 53-8.

77 I. Viarengo, 'Choice of law agreements upon property regimes, divorce and succession: stress-testing the new EU Regulations' [2016] ERA Forum 543, pp. 543-54. 
mejor sirve a sus intereses comunes. ${ }^{78}$ También en este caso, un asesoramiento jurídico adecuado es esencial para que la pareja pueda tomar una decisión que debe orientarse hacia el derecho y el régimen patrimonial más equitativo en relación con su opción sobre la organización de su vida matrimonial o su unión registrada. Esto es especialmente importante, ya que existe una creciente disparidad entre los Estados miembros en cuanto a los mecanismos de protección de la parte más débil. Por ejemplo, en algunos Estados, el régimen por defecto es la "comunidad de bienes" y, en caso de divorcio, la ley establece que la parte más débil reciba una pensión alimenticia periódica por tiempo indefinido o por un periodo razonable. Por el contrario, en otros estados, el régimen por defecto es el de "separación de bienes" y, en caso de divorcio, la parte más débil sólo recibe alimentos en casos excepcionales y por un período determinado. ${ }^{79}$

Algunos riesgos para la parte más débil, relacionados con lo anterior, tienden a dar más espacio a la autonomía privada. La parte más débil puede verse persuadida u obligada a elegir la ley aplicable que prevea el menor nivel de protección, así como a reducir - o incluso renunciar - a la pensión alimenticia después del divorcio (por ejemplo, sobre la base de una ley aplicable en virtud de la cual sean válidos los acuerdos prenupciales o postnupciales). Este riesgo se hace aún más efectivo por el principio de "aplicación universal" del artículo 20 de los Reglamentos gemelos, según el cual también puede aplicarse la ley de un tercer país. ${ }^{80}$

Para evitar estos abusos, la parte más débil debe estar siempre informada sobre las leyes que pueden elegirse y sus consecuencias patrimoniales favorables y desfavorables también con vistas al divorcio. Para ello es necesario que el asesoramiento jurídico prestado a las partes sea justo e imparcial. La protección efectiva de la parte más débil sólo puede garantizarse en un contexto que asegure siempre a la pareja una información adecuada e imparcial, de acuerdo con los Principios del Derecho de Familia Europeo relativos a las relaciones patrimoniales entre los cónyuges. ${ }^{81}$ Si falta dicha información,

78 Esta es una función importante del acuerdo de elección de ley: véase F. Sbordone, 'Potere di scelta della legge applicabile al contratto e funzione delle norme di diritto internazionale privato' [2006] Il diritto civile oggi. Compiti scientifici e didattici del civilista 211, pp. 215-19.

79 Para una visión general de los regímenes de propiedad familiar en los Estados miembros, véase L. Ruggeri, I. Kunda y S. Winkle (coords), Family Property and Succession in EU Member States: National Reports on the Collected Data, Rijeka $2019<$ https:/www.euro-family.eu/documenti/news/psefs_e book_compressed.pdf $>$ accessed 05.05.2021. En los Estados en los que los divorciados pueden encontrar trabajo con facilidad y existen medidas eficaces de ayuda a la renta, el reconocimiento de la prestación postnupcial es excepcional. El principio de autosuficiencia económica también se establece en la parte II del 'Principles of European Family Law Regarding Divorce and Maintenance between Former Spouses' (Principio 2:2). Por el contrario, en los Estados miembros en los que las políticas de bienestar social son escasas e ineficaces, el derecho a la pensión alimenticia se convierte en la principal fuente de ingresos/subsistencia para el ex cónyuge (o pareja) que es económicamente más débil tras la disolución de la relación matrimonial (o de la pareja registrada).

80 El artículo 20 establece que "La ley que se determine aplicable [...] se aplicará aunque no sea la de un Estado miembro". No obstante, conviene precisar que la ley de un tercer Estado elegida por las partes como aplicable a sus relaciones patrimoniales, en circunstancias excepcionales y, en particular, por razones de interés público, puede ser descartada por los órganos jurisdiccionales de los Estados miembros si la aplicación de dicha ley es manifiestamente incompatible con el orden público del Estado miembro en cuestión (véase el artículo 31 de los Reglamentos gemelos).

81 Este conjunto de Principios pertenece a la Principles of European Family Law redactado por la Comisión de Derecho de Familia Europeo (CEFL). Véase el "Principio 4:13 Obligaciones de un notario u otro profesional jurídico que ejerza funciones equivalentes", según el cual "El notario o profesional que ejerza funciones equivalentes debe (a) asesorar imparcialmente a cada uno de los cónyuges de forma separada, (b) asegurar que cada uno de los cónyuges entiende las consecuencias jurídicas de las capitulaciones matrimoniales, y (c) asegurar que ambos 
este defecto puede viciar de hecho el consentimiento prestado por una de las partes y la validez material del acuerdo de elección de la ley debe evaluarse con arreglo a la lex causae hipotética, es decir, la ley que regiría el acuerdo de conformidad con el artículo 22 de los Reglamentos gemelos si fuera válido. ${ }^{82}$ Pero otra salvaguarda para la protección de la parte más débil está prevista en el apartado 2 del artículo 24 de los Reglamentos gemelos. De acuerdo con éste, el cónyuge o la pareja, para demostrar que no dio su consentimiento al acuerdo de elección de la ley aplicable, puede invocar la ley del Estado en el que tenga su residencia habitual en el momento en que se acuda al tribunal. Esto sólo es posible si de las circunstancias se desprende que no sería razonable determinar el efecto de su conducta de acuerdo con la ley designada en el acuerdo. ${ }^{83}$

Sin embargo, los Reglamentos gemelos no prevén expresamente ninguna limitación de la autonomía de las partes en cuanto a las consecuencias del acuerdo de elección de ley, con el fin de proteger a la parte más débil. En su lugar, habría sido conveniente incluir en el texto de este Reglamento una disposición similar a la del apartado 5 del artículo 8 del Protocolo de La Haya de 2007, que establece que "A menos que en el momento de la designación las partes fueran debidamente informadas y conscientes de las consecuencias de la ley designada, ésta no se aplicará cuando conlleve consecuencias manifiestamente injustas o no razonables para cualquiera de las partes" ${ }^{84}$ La cuestión de si este tipo de control judicial del contenido del acuerdo de elección de ley puede aplicarse en los casos que entran en el ámbito de aplicación de los Reglamentos gemelos es una cuestión incierta. ${ }^{85}$ No obstante, se afirma que tales limitaciones a la autonomía de las partes deben aplicarse sobre la base de la hipotética lex causae siempre que ésta sea la ley de un Estado miembro. El principio de equidad y el principio de igualdad entre los cónyuges o parejas pertenecen al núcleo común del Derecho de familia europeo. ${ }^{86}$ Además, si la debilidad económica de una de las partes es más pronunciada debido, por ejemplo, a un problema de salud, las consecuencias del acuerdo de elección de la ley pueden revisarse a la luz de las circunstancias concretas y teniendo en cuenta el principio de solidaridad entre las partes, incluso después de la disolución de la relación, que es común a los valores constitucionales de los Estados miembros.

cónyuges prestan libremente su consentimiento a las capitulaciones" (la cursiva es nuestra). Sobre este principio, véase K. Boele-Woelki, F. Ferrand, C. Gonzáles Beilfuss, M. Jänterä-Jareborg, N. Lowe, D. Martiny y W. Pintens, Principles of European Family Law Regarding Property Relations between Spouses, Intersentia, Cambridge 2013, pp. 126-29.

82 Además, si un cónyuge o pareja se opone a la validez del acuerdo por haber incurrido en un error sobre las consecuencias de la elección, la aplicación de las normas de la lex causae sobre la relevancia de un error o tergiversación debe tener en cuenta el objetivo perseguido por las normas de los Reglamentos gemelos sobre la validez material del acuerdo: C. Kohler, vid. supra n. 5, p. 225.

83 Para más detalles sobre esta disposición, véase C. Kohler, arriba n. 5, pp. 229-31.

84 Cursiva añadida.

85 C. Kohler, vid. supra n. 5, p. 227.

86 Véase lo siguiente CEFL Principles: 'Principio 4:2 Igualdad de los cónyuges'; 'Principio 4:12 Revelación del patrimonio', que es una aplicación de los principios de transparencia y solidaridad; 'Principio 2:10 Acuerdo sobre la pensión de alimentos'. Sobre esta cuestión, véase C. Kohler, vid. supra n. 5, p. 228: cuando el acuerdo conlleva consecuencias manifiestamente injustas para la parte más débil, la revisión del acuerdo de elección de la ley se basaría en el artículo 22 de los Reglamentos gemelos, tal como se interpreta a la luz de la Carta de los Derechos Fundamentales y del Convenio Europeo de Derechos Humanos; según esta opinión, "el criterio para la revisión del contenido del acuerdo se encuentra en el concepto autónomo [del acuerdo de elección de la ley] del artículo 22 y no en el Derecho nacional". 
Desde este punto de vista, la validez del acuerdo de elección de la ley aplicable debería, al menos, poder ser examinada por el tribunal competente.

\section{OBSERVACIONES FINALES}

El rompecabezas que surge de este análisis se complica aún más por el hecho de que la armonización europea no es geográficamente uniforme. Los Reglamentos gemelos sólo se aplican a los Estados miembros que participan en la cooperación reforzada. ${ }^{87} \mathrm{Sin}$ embargo, la autonomía de los partidos debe ser fomentada y promovida, no desalentada.

La elección de la ley aplicable puede ser especialmente importante para las parejas transfronterizas que cambian su residencia habitual durante el tiempo que dura su matrimonio o su relación de pareja. Cuándo y cómo se hace la elección son aspectos esenciales cuyas implicaciones se han analizado en este capítulo.

De acuerdo con los principios esbozados por el TJUE, es necesario interpretar los artículos 22 a 24 de los Reglamentos gemelos teniendo en cuenta no sólo la redacción de dichas disposiciones, sino también el contexto en el que se producen y los objetivos que persiguen las normas de las que forman parte. ${ }^{88}$ Sin embargo, este enfoque requiere una mayor especificación.

Los riesgos asociados tanto al momento como al "contexto" general de la elección de la ley, que se han destacado en este capítulo, pueden ciertamente llevar a las partes a celebrar un acuerdo con consecuencias patrimoniales inciertas y/o injustas, en su perjuicio o en el de la parte más débil. Sin embargo, si se tienen en cuenta adecuadamente estos riesgos, el profesional del derecho guiará a la pareja hacia una elección óptima de la ley aplicable y del régimen patrimonial que rige su matrimonio o unión registrada.

Las cuestiones patrimoniales vienen en su mayoría acompañadas del divorcio, la pensión alimenticia y las responsabilidades parentales. Si el profesional del derecho tiene en cuenta la interacción de los instrumentos de la UE relacionados, se garantizará tanto la seguridad como la concentración de la jurisdicción y la ley aplicable a las relaciones pasadas, presentes y futuras de las partes, independientemente de los cambios en sus vidas individuales y conjuntas. Para ello, debe proporcionarse a las partes un asesoramiento jurídico adecuado. Esto significa que las partes deben recibir información correcta, completa e imparcial, en un lenguaje sencillo y comprensible, y destacando las consecuencias favorables y desfavorables de cada posible elección tanto para la pareja como para cada parte. Si es necesario, deben preverse medidas de equilibrio adecuadas para proteger a la parte más débil.

De ello se desprende que no se trata exclusivamente de un problema de validez formal del acuerdo de elección de ley y/o de elección de foro. También es necesario que el acuerdo se celebre respetando el principio de equidad y los valores de igualdad de dig-

87 Sobre la cooperación reforzada y su repercusión en la autonomía de la voluntad en el marco del Reglamento de régimen económico matrimonial, véase A. Limante y N. Pogorelčnik Vogrinc, 'Party Autonomy in the Context of Jurisdictional and Choice of Law Rules of Matrimonial Property Regulation' [2020] 13 Baltic Journal of Law \& Politics 135, $140 \mathrm{~s}$.

88 Véanse el asunto C-214/17, Alexander Mölk v. Valentina Mölk, vid supra n. 29, point 27; asunto C-184/14, A v. B, ECLI:EU:C:2015:479, punto 32. 
nidad de las partes, equidad social y solidaridad. Estos valores constituyen, en efecto, la base tanto del Derecho de familia europeo como de la Carta de Derechos Fundamentales de la UE, así como del "derecho" de cada Estado miembro. La relevancia normativa de estos principios y valores podría considerarse una amenaza para la seguridad jurídica. Sin embargo, "si el intérprete [...] se niega a emplear los principios jurídicos, no encontrará la solución que mejor se adapte a las características específicas del caso concreto, ya que el ‘derecho' es una experiencia más amplia que la mera aplicación de normas" ${ }^{89}$

89 P. Perlingieri, 'Legal Principles and Values' (2017) 3 The Italian Law Journal, 125, 125-47. 